\title{
A Dual-Readout Tyrosinase Activity Assay Facilitated by Chromo- fluorogenic Reaction between Catechols and Naphthoresorcin
}

Jiahui Zhao ${ }^{\dagger, \S}$, Guoyong Liu ${ }^{\dagger, \star}$, Jian Sun*,†, Qifeng Wang, Zong-Jun Li ${ }^{\dagger}$, and Xiurong Yang* $*, \$, \$$

†State Key Laboratory of Electroanalytical Chemistry, Changchun Institute of Applied Chemistry,

Chinese Academy of Sciences, Changchun, Jilin 130022, China

$\S$ University of Chinese Academy of Sciences, Beijing 100049, China

University of Science and Technology of China, Hefei, Anhui 230026, China

"International Joint Research Laboratory of Nano-Micro Architecture Chemistry (NMAC), Department of Organic Chemistry, College of Chemistry, Jilin University, Changchun, Jilin 130012, China

*Fax: +8643185689278. E-mail: jiansun@ciac.ac.cn, xryang@ciac.ac.cn 


\begin{abstract}
SI:
Figure S1. (A) Absorbance and (C) fluorescence emission spectra of the product solution of hydroxytyrosol reacting with $\mathrm{NR}$, (B) $\mathrm{A}_{458}$ and (D) $\mathrm{I}_{480}$ of the product solution with varied $\mathrm{pH}$ values.
\end{abstract}

Figure S2. (A) Real-time $A_{458}$ and (B) $I_{480}$ of the product solution with different $\mathrm{pH}$ values.

Figure S3. ${ }^{1} \mathrm{H}$ NMR spectrum of the resultant product between hydroxytyrosol and NR in DMSO- $\mathrm{d}_{6}$.

Figure S4. ${ }^{13} \mathrm{C}$ NMR spectrum of the resultant product between hydroxytyrosol and NR in DMSO- $\mathrm{d}_{6}$.

Figure S5. The high-resolution mass spectrum of the resultant product between hydroxytyrosol and naphthoresorcin $\mathrm{H}_{2} \mathrm{O}$.

Figure S6. The fluorescence intensity of the product solution versus absorbance values with fluorescein as the reference.

Figure S7. (A) Structural formula of neutral and anionic species of 1 in aqueous solution. The optimized conformation and frontier orbital energy of neutral species (B) and anionic species (C) of 1 from Gaussian calculation. ${ }^{1}$

Figure S8. Calculated absorbance and fluorescence emission spectra of neutral and anionic species of 1 from Gaussian calculations.

Figure S9. (A) Absorption spectra and (C) fluorescence emission spectra of the tyrosinase-triggered reaction at different concentrations of tyrosol. (B) $A_{458}$ and (D) $I_{480}$ of the proposed system.

Figure S10. (A) Absorption spectra and (C) fluorescence emission spectra of the tyrosinase-triggered reaction as a function of different concentrations of NR. (B) $A_{458}$ and (D) $I_{480}$ of the proposed system.

Figure S11. (A) Absorption spectra and (C) fluorescence emission spectra of the tyrosinase-triggered reaction as a function of different $\mathrm{pH}$ values. (B) $A_{458}$ and (D) $I_{480}$ of the proposed system.

Figure S12. (A) $A_{458}$ and (B) $I_{480}$ of the proposed system with different tyrosinase incubation time.

Figure S13. (A) Absorption spectra and (C) fluorescence emission spectra versus different tyrosinase concentrations in 5\% FBS. (B) $A_{458}$ and (D) $I_{480}$ of the proposed system.

Table S1. Comparison of performance of different tyrosinase sensors.

Figure S14 (A) Fluorescence emission spectra and (B) Kinetic plots of $I_{480}$ with different concentrations of kojic acid. 

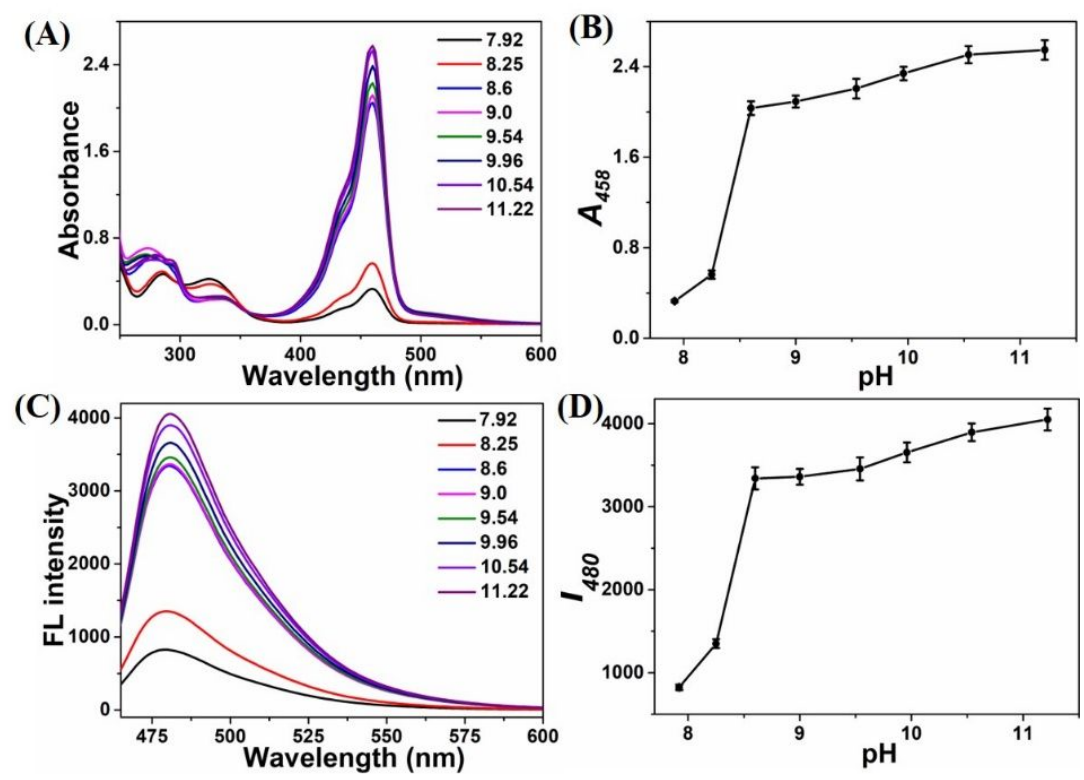

Figure S1. (A) Absorbance and (C) fluorescence emission spectra of the product solution of hydroxytyrosol reacting with NR and as a function of $\mathrm{pH}$ values. (B) Absorbance values at $458 \mathrm{~nm}$ $\left(A_{458}\right)$ and $(\mathrm{D})$ fluorescence intensity at $480 \mathrm{~nm}\left(I_{480}\right)$ of the product solution with varied $\mathrm{pH}$ values. (The initial concentration of hydroxytyrosol and NR were both $200 \mu \mathrm{M}$, and the product solution was diluted by five and fivety times before absorbance and fluorescence measurement, respectively). All the measurements were performed in $20 \mathrm{mM}$ sodium carbonate buffer $(\mathrm{pH}=11.0)$ at room temperature, $\lambda_{\mathrm{ex}}=460 \mathrm{~nm}$.
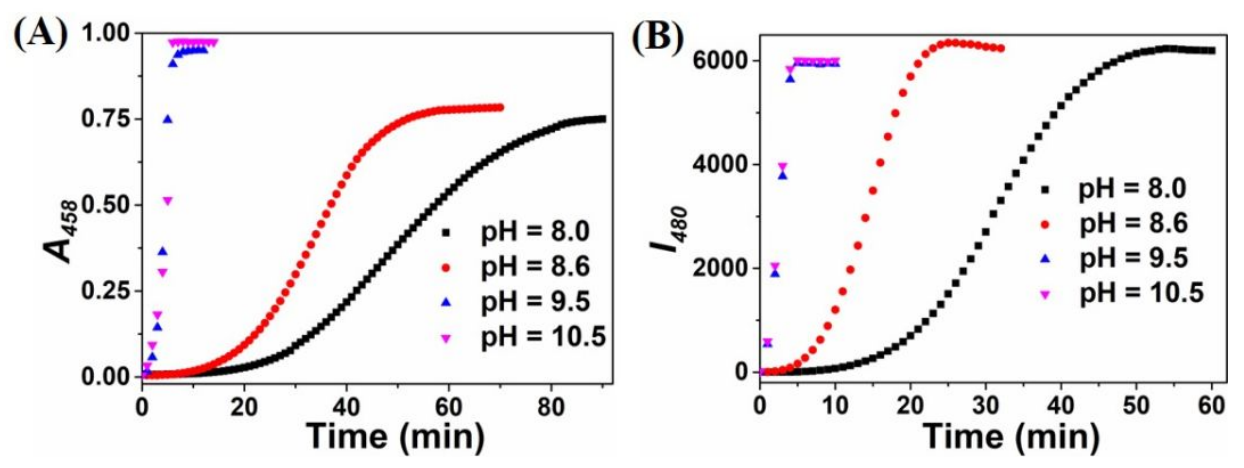

Figure S2. (A) Real-time $A_{458}$ and (B) $I_{480}$ of the product solution of hydroxytyrosol and NR in 20 $\mathrm{mM} \mathrm{NaHCO} 3$ buffer with different $\mathrm{pH}$ values. (The initial concentration of hydroxytyrosol and NR were both $20 \mu \mathrm{M}$.) All the measurements were performed at room temperature, $\lambda_{\mathrm{ex}}=460 \mathrm{~nm}$. 


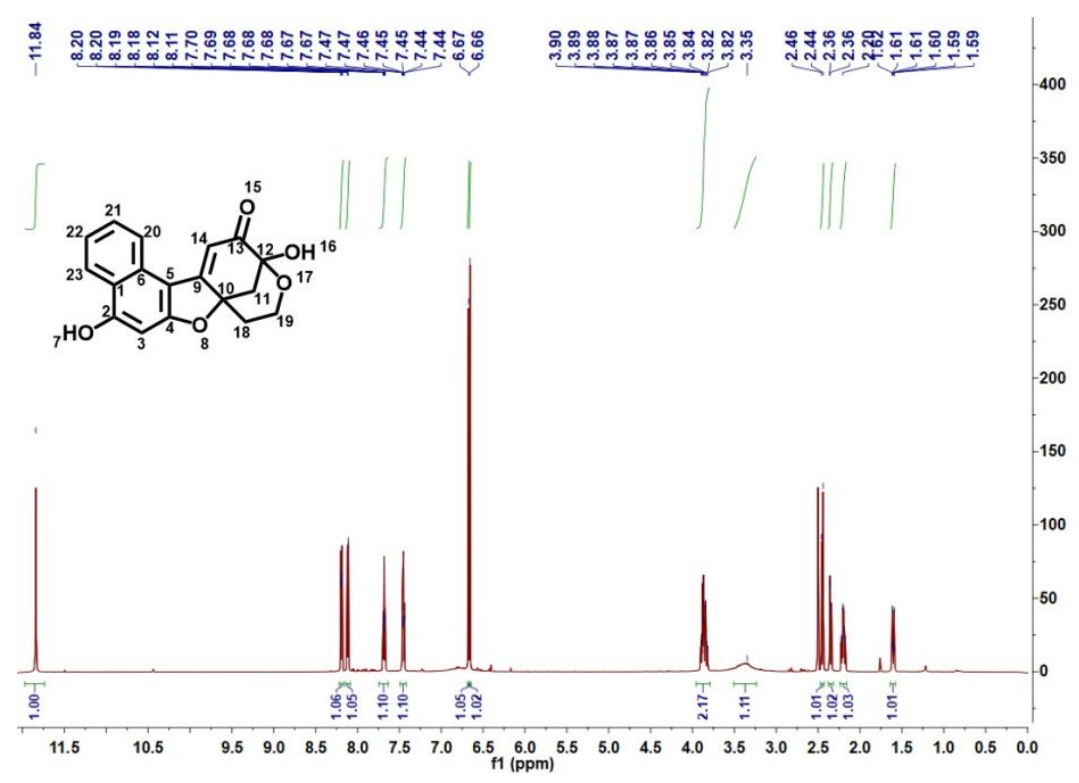

Figure S3. ${ }^{1} \mathrm{H}$ NMR spectrum of the resultant product between hydroxytyrosol and NR in DMSO$d_{6}$.

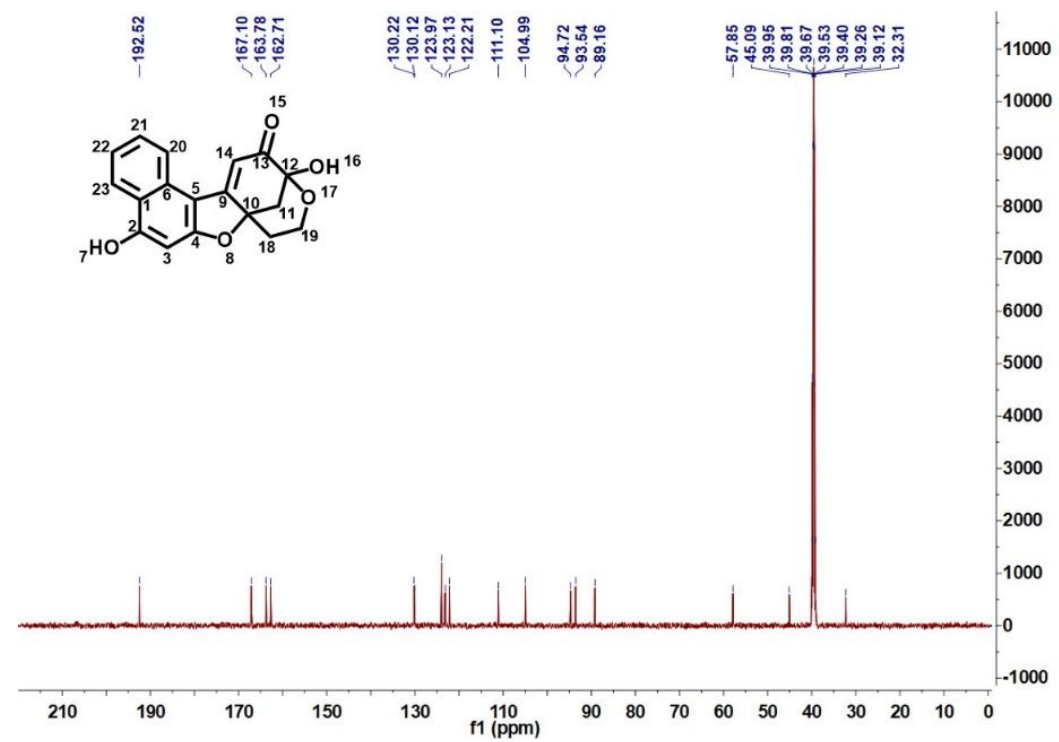

Figure S4. ${ }^{13} \mathrm{C}$ NMR spectrum of the resultant product between hydroxytyrosol and NR in DMSO- $\mathrm{d}_{6}$. 


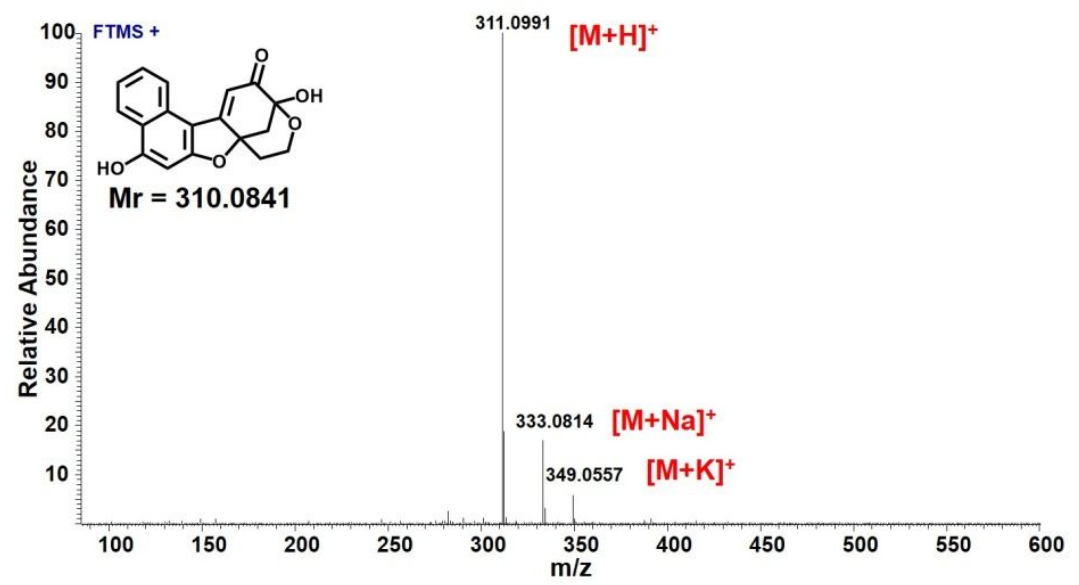

Figure S5. The high-resolution mass spectrum of the resultant product between hydroxytyrosol and naphthoresorcin $\mathrm{H}_{2} \mathrm{O}$.
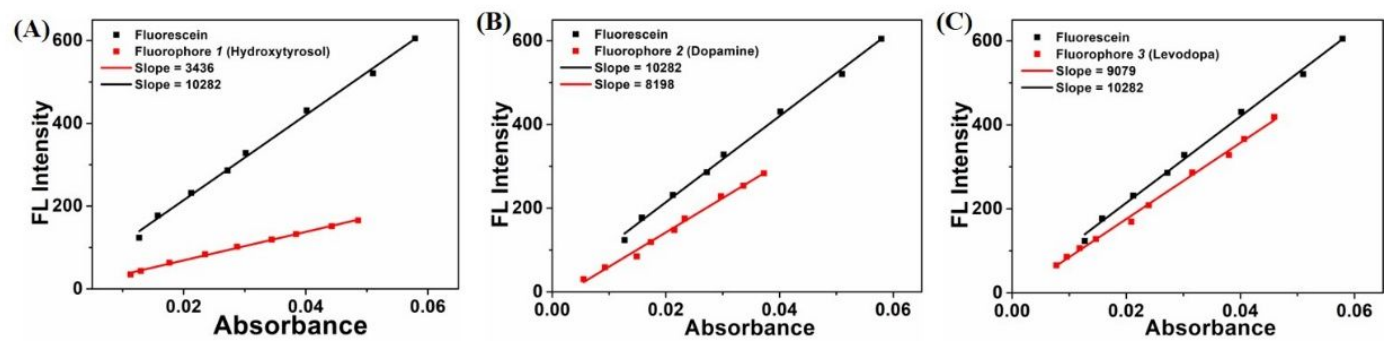

Figure S6. The fluorescence intensity $\left(I_{480}\right)$ of the produced fluorophore solution versus absorbance $\left(A_{458}\right)$ values with fluorescein $\left(I_{511}\right.$ versus $\left.A_{491}\right)$ as the reference, and the measurement was performed in $0.1 \mathrm{M} \mathrm{NaOH}$ solution at room temperature $\left(22^{\circ} \mathrm{C}\right)$. The calculated slope is proportional to the quantum yield of the fluorophore.

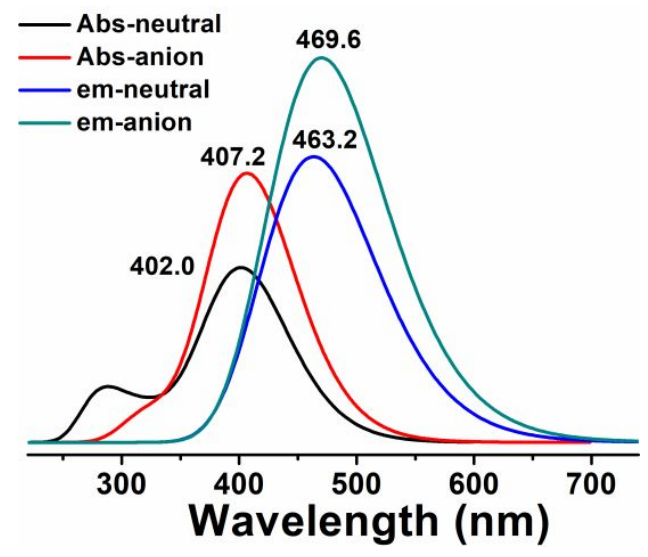

Figure S7. Calculated absorbance (Abs) and fluorescence emission (em) spectra of neutral and anionic species of 1 from Gaussian calculations. 


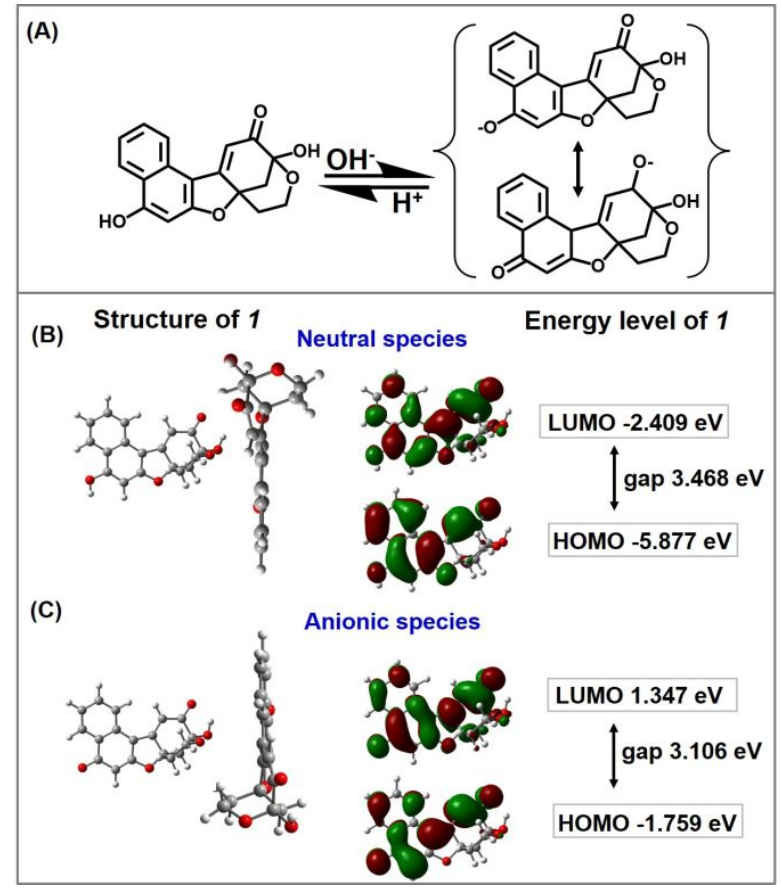

Figure S8. (A) Structural formula of neutral and anionic species of 1 in aqueous solution. The optimized conformation and frontier orbital energy of neutral species (B) and anionic species (C) of 1 from Gaussian calculation. ${ }^{1}$
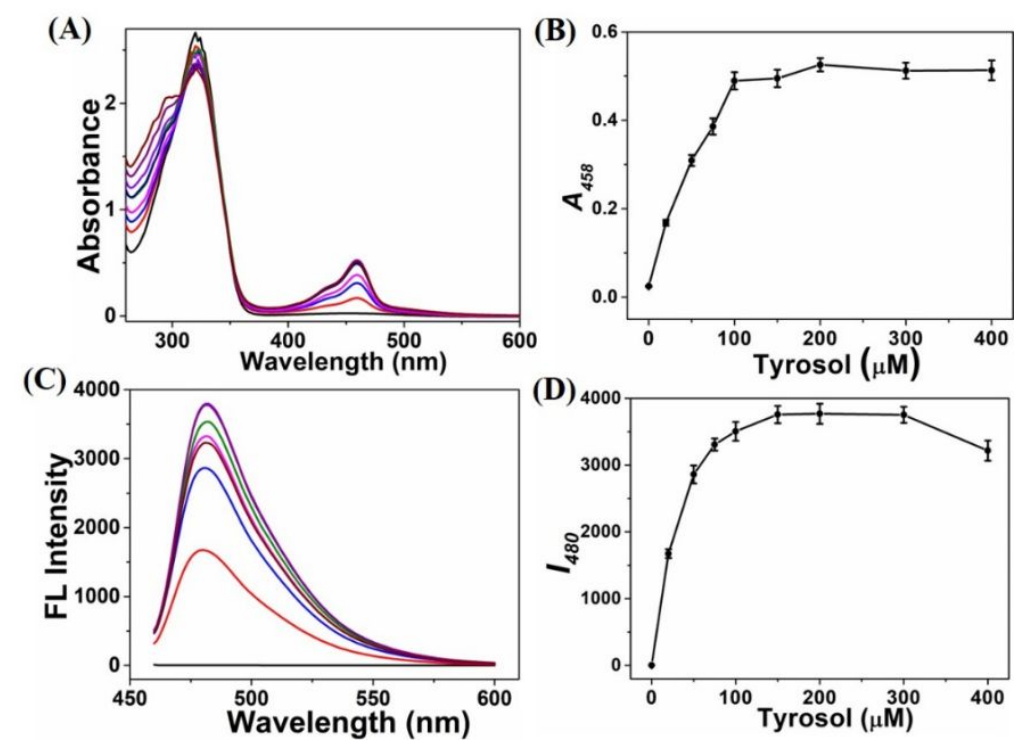

Figure S9. (A) Absorption spectra and (C) fluorescence emission spectra of the tyrosinase-triggered reaction with different concentrations of tyrosol. (B) $A_{458}$ and (D) $I_{480}$ of the proposed system. (the concentrations of tyrosinase and NR were $1 \mathrm{U} / \mathrm{mL}$ and $200 \mu \mathrm{M}$, respectively. The fluorescence spectra were monitored after dilution by five times.) 

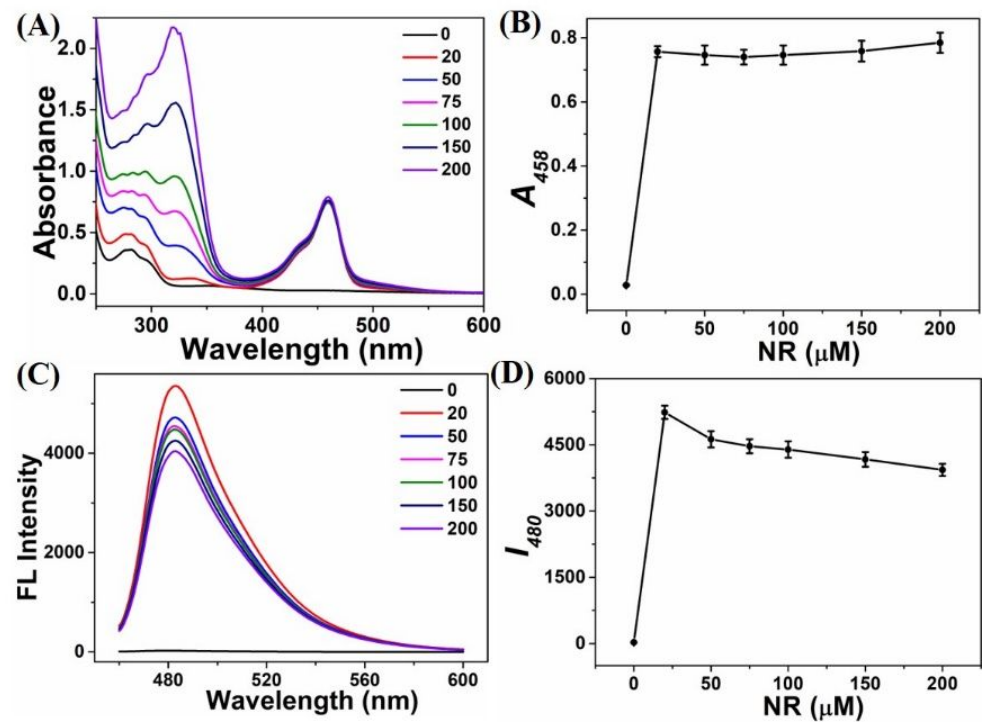

Figure S10. (A) Absorption spectra and (C) fluorescence emission spectra of the tyrosinasetriggered reaction as a function of different concentrations of NR. (B) $A_{458}$ and (D) $I_{480}$ of the proposed system. (The concentrations of tyrosinase and tyrosol were $1 \mathrm{U} / \mathrm{mL}$ and $200 \mu \mathrm{M}$, respectively. The fluorescence spectra were monitored after dilution by five times.)
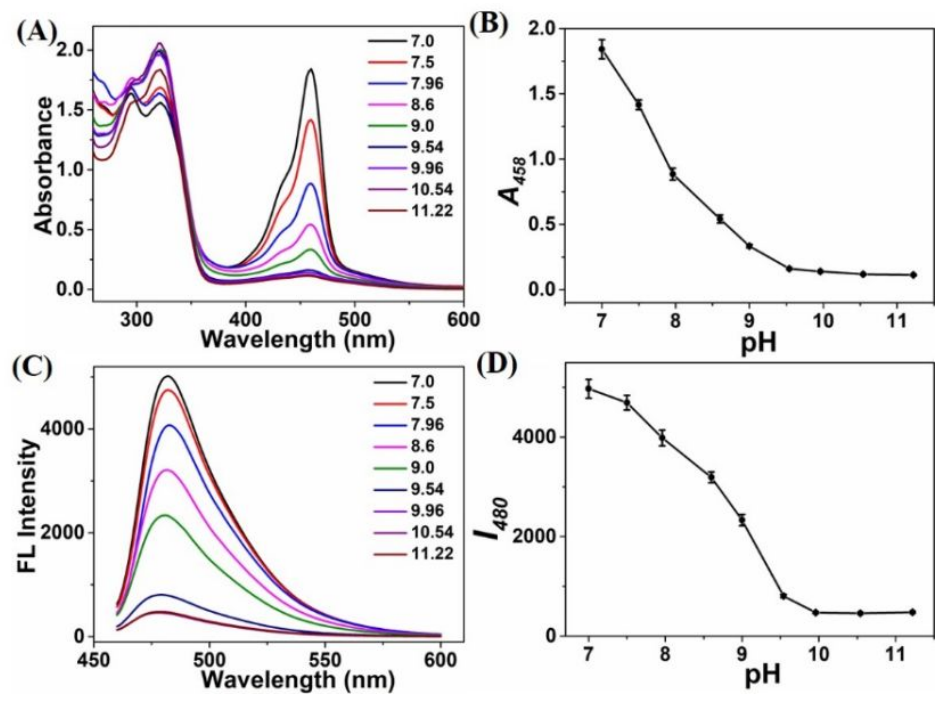

Figure S11. (A) Absorption spectra and (C) fluorescence emission spectra of the tyrosinasetriggered reaction as a function of different $\mathrm{pH}$ values. (B) $A_{458}$ and (D) $I_{480}$ of the proposed system. (the concentrations of tyrosinase, tyrosol, and NR were $1 \mathrm{U} / \mathrm{mL}, 200 \mu \mathrm{M}$, and $200 \mu \mathrm{M}$, respectively. The fluorescence spectra were monitored after dilution by five times.) 

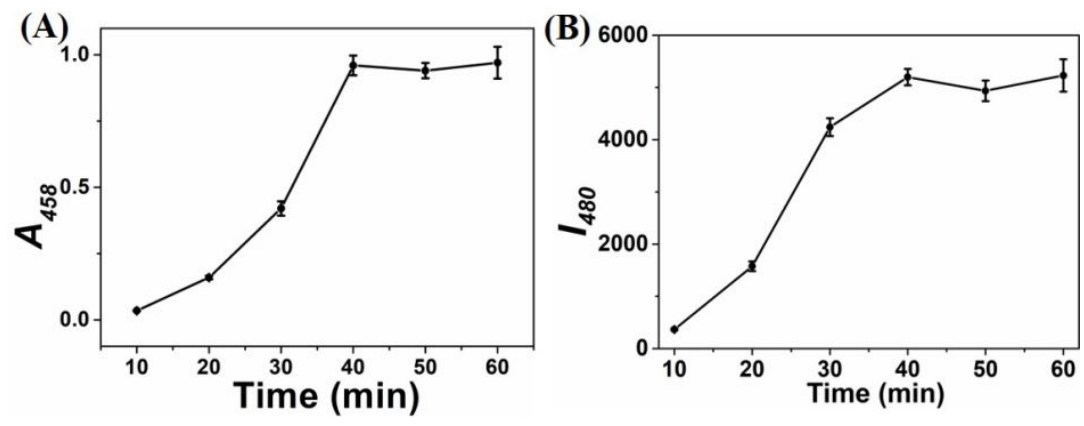

Figure S12. (A) $A_{458}$ and (B) $I_{480}$ of the proposed system with different tyrosinase incubation time. (the concentration of tyrosinase was $1 \mathrm{U} / \mathrm{mL}$.)
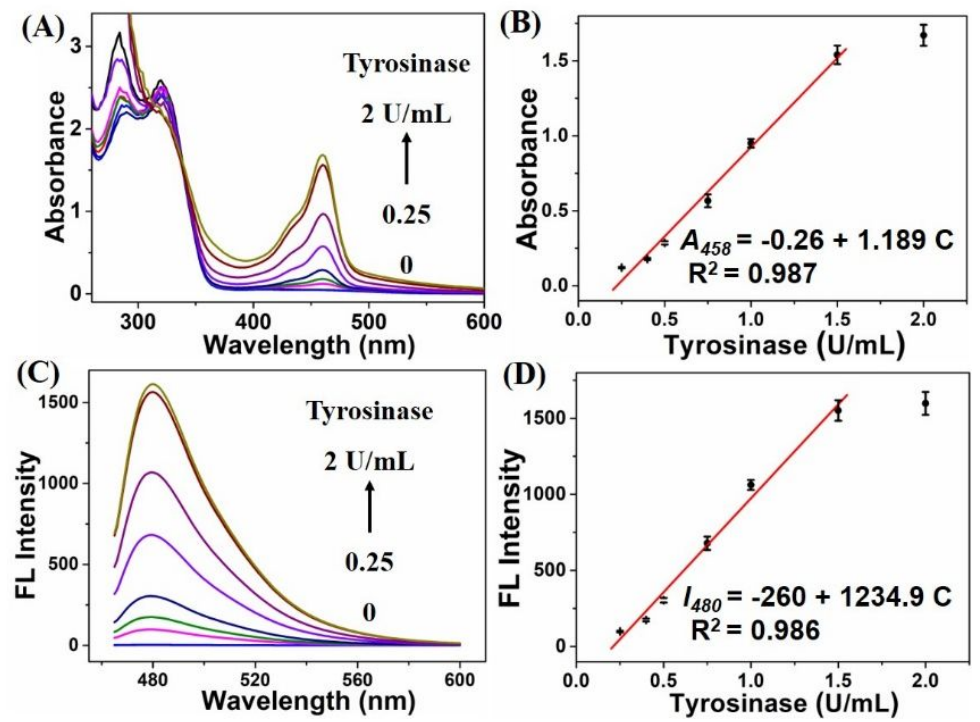

Figure S13. (A) Absorption spectra and (C) fluorescence emission spectra versus different tyrosinase concentrations in 5\% FBS. (B) $A_{458}$ and (D) $I_{480}$ of the proposed system. (The concentrations of tyrosol and NR were both $200 \mu \mathrm{M}$, and the fluorescence spectra were monitored after dilution by ten times.) 
Table S1. Comparison of performance of different tyrosinase sensors.

\begin{tabular}{|c|c|c|c|}
\hline $\begin{array}{l}\text { Fluorescent sensing } \\
\text { system }\end{array}$ & Synthesis condition & Linear range & References \\
\hline NBR-AP & $\begin{array}{l}6 \text { synthesis and purification steps } \\
\qquad 0-90^{\circ} \mathrm{C} 50 \mathrm{~h}\end{array}$ & $20-200 \mathrm{U} / \mathrm{mL}$ & 2 \\
\hline HB-NP & $\begin{array}{l}5 \text { synthesis and purification steps } \\
\qquad 0-75^{\circ} \mathrm{C} 14 \mathrm{~h} \\
3 \text { synthesis and purification steps }\end{array}$ & - & 3 \\
\hline NIR & $0-50^{\circ} \mathrm{C} 12.5 \mathrm{~h}$ & $10-70 \mu \mathrm{g} / \mathrm{mL}$ & 4 \\
\hline $\begin{array}{l}\text { ROX-DNA- } \\
\text { CdZnTeS QDs }\end{array}$ & $200^{\circ} \mathrm{C} 17 \mathrm{~min}$ & $10-100 \mathrm{ng} / \mathrm{mL}$ & 5 \\
\hline Cyanine-based probe & $\begin{array}{l}4 \text { synthesis and purification steps } \\
\qquad 0-80^{\circ} \mathrm{C} 24 \mathrm{~h}\end{array}$ & $0.07-5.0 \mathrm{U} / \mathrm{mL}$ & 6 \\
\hline DCM & & $0.5-100 \mathrm{U} / \mathrm{mL}$ & 7 \\
\hline Si NPs & $\begin{array}{c}150{ }^{\circ} \mathrm{C} 2 \mathrm{~h} \\
\text { Dialysis for } 6 \mathrm{~h}\end{array}$ & $0.6-6 \mathrm{U} / \mathrm{mL}$ & 8 \\
\hline $\begin{array}{l}\text { Modified methylene blue } \\
\qquad \text { MB1 }\end{array}$ & $\sim 12 \mathrm{~h}$ & $0.01-1 \mathrm{U} / \mathrm{mL}$ & 9 \\
\hline Resorufin based probe & $60^{\circ} \mathrm{C} 24 \mathrm{~h}$ & $1-90 \mathrm{U} \mathrm{mL}^{-1}$ & 10 \\
\hline 4-hydroxyphenyl HXPI & $\begin{array}{l}4 \text { synthesis and purification steps } \\
\qquad 0-60^{\circ} \mathrm{C} 10 \mathrm{~h}\end{array}$ & $1-80 \mathrm{U} / \mathrm{mL}$ & 11 \\
\hline Tyrosol & $\begin{array}{l}\text { without purification step } \\
\text { R.T. } 20 \mathrm{~min}\end{array}$ & $\begin{array}{l}0.02-1.5 \mathrm{U} / \mathrm{mL} \\
0.01-1 \mathrm{U} / \mathrm{mL}\end{array}$ & This work \\
\hline
\end{tabular}



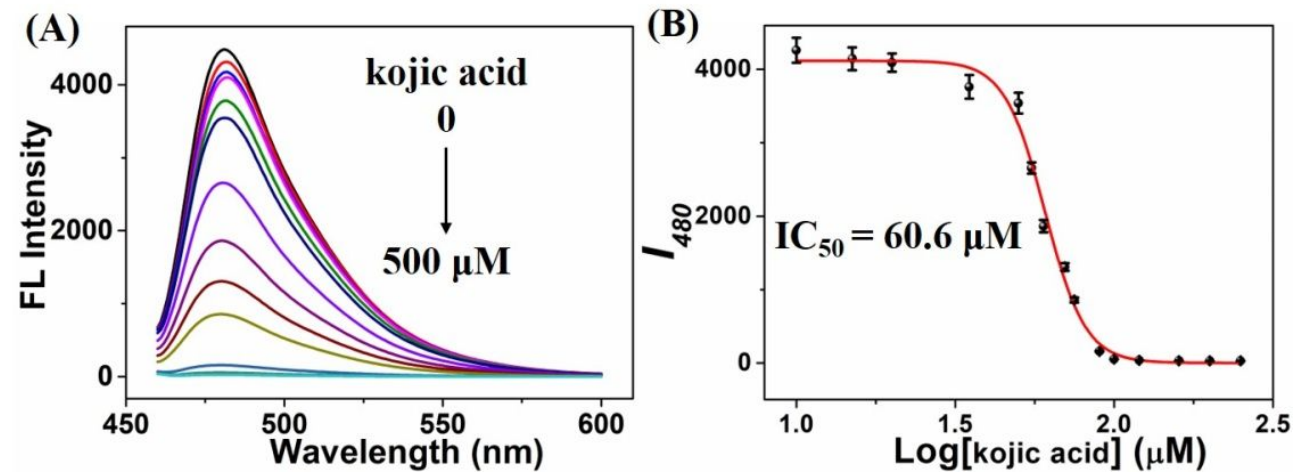

Figure S14. (A) Fluorescence emission spectra and (B) Kinetic plots of $I_{480}$ with different concentrations of kojic acid. (The concentrations of tyrosinase, tyrosol and NR were $1 \mathrm{U} / \mathrm{mL}, 200$ $\mu \mathrm{M}$, and $200 \mu \mathrm{M}$, respectively.)

\section{References :}

(1) Yang, W. W.; Li, Z. J.; Li, S. H.; Gao, X. J. Phys. Chem. A 2015, 119, 9534-9540.

(2) Zhan, C.; Cheng, J.; Li, B.; Huang, S.; Zeng, F.; Wu, S. Anal. Chem. 2018. 90, 88078815.

(3) Peng, M.; Wang, Y.; Fu, Q.; Sun, F.; Na, N.; Ouyang, J. Anal. Chem. 2018, 90, 62066213.

(4) Zhang, J.; Li, Z.; Tian, X.; Ding, N. Chem. Commun. 2019, 55, 9463-9466.

(5) Mao, G.; Du, M.; Wang, X.; Ji, X.; He, Z. Analyst 2018, 143, 5295-5301.

(6) Zhang, P.; Li, S.; Fu, C.; Zhang, Q.; Xiao, Y.; Ding, C. Analyst 2019, 144, 5472-5478.

(7) Li, Q.; Yan, C.; Zhang, J.; Guo, Z.; Zhu, W.-H. Dyes Pigments 2019, 162, 802-807.

(8) Ding, Y. Z.; Wang, W. F.; Chai, T.; Qiang, Y.; Shi, Y. P.; Yang, J. L. Talanta 2019, 197, 113-121.

(9) Li, Z.; Wang, Y. F.; Zeng, C.; Hu, L.; Liang, X. J. Anal. Chem. 2018, 90, 3666-3669.

(10) Wu, X.; Li, X.; Li, H.; Shi, W.; Ma, H. Chem. Commun. 2017, 53, 2443-2446.

(11) Wu, X. F.; Li, L. H.; Shi, W.; Gong, Q. Y.; Ma, H. M. Angew. Chem. Int. Edit. 2016, 55, 
14728-14732. 